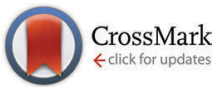

Cite this: Chem. Commun., 2015, 51,6568

Received 24th February 2015, Accepted 10th March 2015

DOI: $10.1039 / c 5 c c 01580 d$

www.rsc.org/chemcomm

\section{Visible light photooxidation of nitrate: the dawn of a nocturnal radical $\dagger$}

\author{
T. Hering, ${ }^{a}$ T. Slanina, ${ }^{a}$ A. Hancock, ${ }^{b}$ U. Wille ${ }^{\star^{b}}$ and B. König ${ }^{{ }^{a}}$
}

\begin{abstract}
Highly oxidizing nitrate radicals $\left(\mathrm{NO}_{3}{ }^{\circ}\right)$ are easily accessed from readily available nitrate salts by visible light photoredox catalysis using a purely organic dye as the catalyst and oxygen as the terminal oxidant. The interaction of the excited catalyst and nitrate anions was studied by spectroscopic methods to elucidate the mechanism, and the method was applied to the $\mathrm{NO}_{3}{ }^{\cdot}$ induced oxidation of alkynes and alcohols.
\end{abstract}

The nitrate radical $\left(\mathrm{NO}_{3}{ }^{\bullet}\right)$ is the most important nocturnal free radical oxidant in the troposphere and thus accounts for the majority of the oxidative reactions at night-time. ${ }^{1}$ In the atmosphere $\mathrm{NO}_{3}{ }^{\bullet}$ oxidizes a broad scope of volatile organic species including alkenes, ${ }^{2,3}$ alcohols, ${ }^{4,5}$ terpenes, ${ }^{1}$ esters,${ }^{6}$ and sulfides. ${ }^{1}$ It is a highly reactive and chemically versatile $O$-centered radical $^{7}$ with an oxidation potential of $+2.00 \mathrm{~V}$ ( $v s$. SCE in MeCN). ${ }^{8}$ Apart from electron transfer (ET), ${ }^{9,10} \mathrm{NO}_{3}{ }^{\bullet}$ also reacts by addition to $\pi$ systems $^{1,11}$ and by hydrogen atom abstraction (HAT). ${ }^{8,12,13}$ Overall, the reactivity of $\mathrm{NO}_{3}{ }^{\bullet}$ with organic molecules can be seen in between that of hydroxyl radicals $\left(\mathrm{OH}^{\bullet}\right)$ and sulfate radical anions $\left(\mathrm{SO}_{4}{ }^{--}\right) \cdot{ }^{14}$

Despite its high chemical versatility, it is surprising that only limited synthetic applications of $\mathrm{NO}_{3}{ }^{\bullet}$ are available so far. Shono reported the addition of electrochemically generated $\mathrm{NO}_{3}{ }^{\bullet}$ to alkenes. ${ }^{11}$ The reaction of $\mathrm{NO}_{3}{ }^{\bullet}$ with cyclic alkynes and alkynones was employed to obtain cis-fused bicyclic ketones in selfterminating oxidative radical cyclizations. ${ }^{15,16}$ This concept was later extended to alkyne ethers yielding tetrasubstituted tetrahydrofurans. ${ }^{17,18}$ One reason for the limited use of $\mathrm{NO}_{3}{ }^{\bullet}$ as a reagent in organic transformations is its rather difficult accessibility. Common methods for $\mathrm{NO}_{3}{ }^{\bullet}$ generation on preparative scale in solution are the reaction of nitrogen dioxide and ozone, ${ }^{1,19}$ electrooxidation of nitrate anions ${ }^{11}$ or the photolysis of $\left(\mathrm{NH}_{4}\right)_{2} \mathrm{Ce}\left(\mathrm{NO}_{3}\right)_{6}(\mathrm{CAN})$ with UV light $(\lambda=350 \mathrm{~nm})^{14,20}$

\footnotetext{
${ }^{a}$ Institut für Organische Chemie, Universität Regensburg, Universitätsstrasse 31, D-93053 Regensburg, Germany. E-mail: burkhard.koenig@ur.de

${ }^{b}$ School of Chemistry and BIO21 Molecular Science and Biotechnology Institute, The University of Melbourne, 30 Flemington Road, Parkville, VIC 3010, Australia. E-mail: uwille@unimelb.edu.au

$\dagger$ Electronic supplementary information (ESI) available. See DOI: 10.1039/c5cc01580d
}

However, the use of toxic gases, high electrode potentials, ${ }^{8}$ or UV irradiation are so far limiting the applications and lead to undesired side reactions.

We were pleased to observe that, upon excitation of the organic photocatalyst 9-mesityl-10-methylacridinium perchlorate (1) with blue light, oxidation of nitrate anions to $\mathrm{NO}_{3}{ }^{\bullet}$, readily occurs (Scheme 1), thus providing a convenient access to $\mathrm{NO}_{3}{ }^{\bullet}$ on a preparative scale. 9-Mesityl-10-methylacridinium perchlorate (1) was chosen, because it is known to have a strong oxidizing capacity in the excited state. ${ }^{21,22}$ To the best of our knowledge, this is the first visible light mediated generation of nitrate radicals.

In order to elucidate the mechanism of the $\mathrm{NO}_{3} \cdot$ formation, we monitored the generation of reduced catalyst Acr-Mes in the presence of $\mathrm{LiNO}_{3}$ upon continuous irradiation of a $5 \mu \mathrm{M}$ solution of Acr $^{+}$-Mes (1) in MeCN with $455 \mathrm{~nm}$ light under

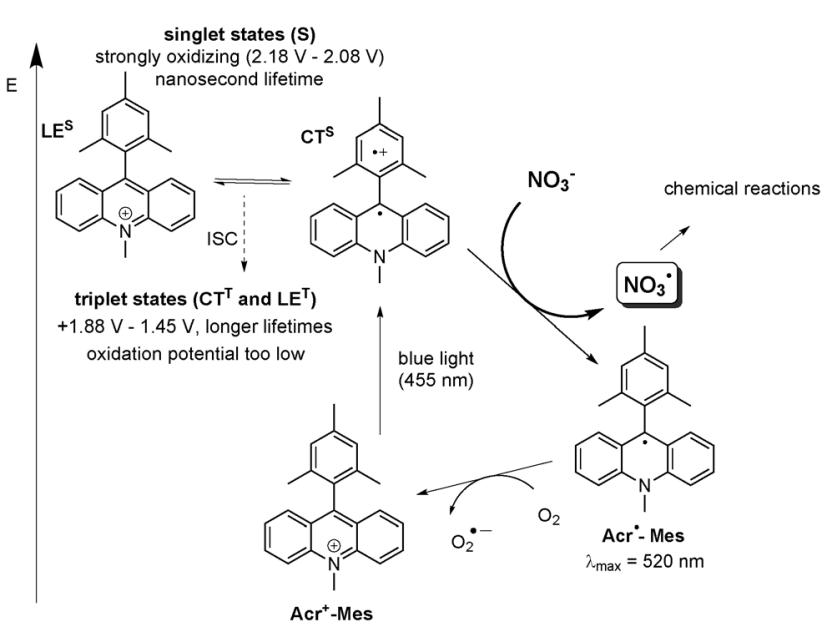

Scheme 1 Proposed mechanism of visible light mediated generation of $\mathrm{NO}_{3} \cdot$ via photocatalytic oxidation by $\mathrm{Acr}^{+}-\mathrm{Mes}(\mathbf{1})$. The electron transfer from $\mathrm{NO}_{3}{ }^{-}$occurs from the short-lived singlet state $\left(\mathrm{LE}^{\mathrm{S}}\right.$ or $\left.\mathrm{CT}^{\mathrm{S}}\right)$ with sufficient oxidative capacity to generate the reduced catalyst Acr $^{\circ}$-Mes and $\mathrm{NO}_{3}{ }^{\bullet}$, the longer lived transient triplet species $\left(\mathrm{CT}^{\top}\right.$ or $\left.\mathrm{LE}^{\top}\right)$ is not reactive towards $\mathrm{NO}_{3}{ }^{-}$. The reduced catalyst Acr-Mes is regenerated by oxygen. (All oxidation potentials are given vs. SCE in $\mathrm{MeCN}$ or $\mathrm{PhCN}$ ). 23,25,26 
anaerobic conditions. The differential absorption spectrum shows the appearance of Acr-Mes with a maximum at $520 \mathrm{~nm}^{21,23}$ after irradiation for $120 \mathrm{~s}$ and $240 \mathrm{~s}$. (see ESI, $†$ Fig. S6) This observation suggests a direct oxidation of $\mathrm{NO}_{3}{ }^{-}$by the excited catalyst thus demonstrating that $\mathrm{NO}_{3}{ }^{-}$can act as an electron donor to the excited catalyst. The reduced catalyst $\mathbf{A c r}^{\circ}$-Mes is stable under argon, however, the signal vanishes completely after aeration of the reaction mixture due to reoxidation of Acr-Mes to the ground state catalyst Acr-Mes by oxygen (see Scheme 1). ${ }^{24}$ The negative signal at $\lambda<460 \mathrm{~nm}$ in the differential absorption spectrum is caused mainly by the decrease of the ground state absorption of Acr-Mes as a result of Acr-Mes formation and partial photobleaching of Acr-Mes. $\$$ The long-lived triplet state with a microsecond lifetime is generally discussed as the reactive state in most oxidative reactions. ${ }^{25,26}$ The exact nature of this state is controversial and could be both a $\mathrm{CT}^{\mathrm{T}}$ state with an oxidation potential of $+1.88 \mathrm{~V} v$ s. SCE, as reported by Fukuzumi ${ }^{25}$ or a locally excited triplet state, $\mathrm{LE}^{\mathrm{T}}$, with an oxidation potential of $+1.45 \mathrm{~V} v$ s. SCE as reported by Verhoeven ${ }^{26}$ However, neither would have the oxidative capacity to oxidize $\mathrm{NO}_{3}{ }^{-}$. Recent detailed mechanistic investigations by the group of Nicewicz revealed that for substrates with oxidation potentials exceeding $+1.88 \mathrm{~V}$ ( $v s$. SCE), a reaction should occur out of the short-lived excited singlet state (mainly $\mathrm{CT}^{\mathrm{S}}$ ), which has an estimated oxidation potential of $2.08 \mathrm{~V}$ (Scheme 1). ${ }^{23}$ Since both singlet states are fluorescent $\left(\phi_{\mathrm{F}} \sim 8 \%\right)$, whereas the triplet states do not emit, ${ }^{23}$ we performed fluorescence quenching experiments to explore the nature of the reactive state involved in $\mathrm{NO}_{3}{ }^{-}$oxidation. A clear quenching of the fluorescence by $\mathrm{LiNO}_{3}$ confirms that oxidation of $\mathrm{NO}_{3}{ }^{-}$occurs from the singlet excited state of 1 (see ESI, $\dagger$ Fig. S6). Moreover, laser flash photolysis experiments confirmed that no interaction of the long lived triplet state and $\mathrm{NO}_{3}{ }^{-}$can be observed (Fig. S8 in the ESI $\dagger$ ). Based on these findings, we suggest that the reaction proceeds via a singlet excited state as depicted in Scheme 1.

Having demonstrated the pathway for photocatalytic $\mathrm{NO}_{3}{ }^{\bullet}$ generation, we selected the well-studied reaction of $\mathrm{NO}_{3}{ }^{\bullet}$ with diphenylacetylene (2) yielding benzil (3) and benzophenone (4) to explore the synthetic application of this new method and to compare it with the previously reported methods. The results are compiled in Table 1. Under photocatalytic conditions using $5 \mathrm{~mol} \%$ of Acr $^{+}$-Mes (1), $0.25 \mathrm{mmol}$ of alkyne 2 and 2 eq. of $\mathrm{LiNO}_{3}$, diketone 3 and ketone 4 were obtained after $2 \mathrm{~h}$ of irradiation with blue light $(\lambda=455 \mathrm{~nm})$ with yields comparable to previous methods. ${ }^{27}$ When oxygen was replaced by ammonium persulfate as the electron acceptor in a degassed system, the yield and product ratio were not changed significantly (entry 5). This shows that potential interfering reactions by singlet oxygen could be excluded. In the absence of light or catalyst no reaction occurred (entries 7 and 9). However, small amounts of diketone 3 were formed in the direct reaction of 2 with the excited catalyst in the absence of nitrate ions (entry 8).

According to computational studies, the mechanism for the $\mathrm{NO}_{3} \cdot$ induced oxidation of diphenylacetylene suggests formation of diketone 3 and benzophenone (4) through competing pathways in the initial vinyl radical adduct 5 (Scheme 2). While diketone 3 results from a 5-endo cyclization, followed by loss
Table 1 Oxidation of diphenylacetylene 2 by $\mathrm{NO}_{3}{ }^{\bullet a}$

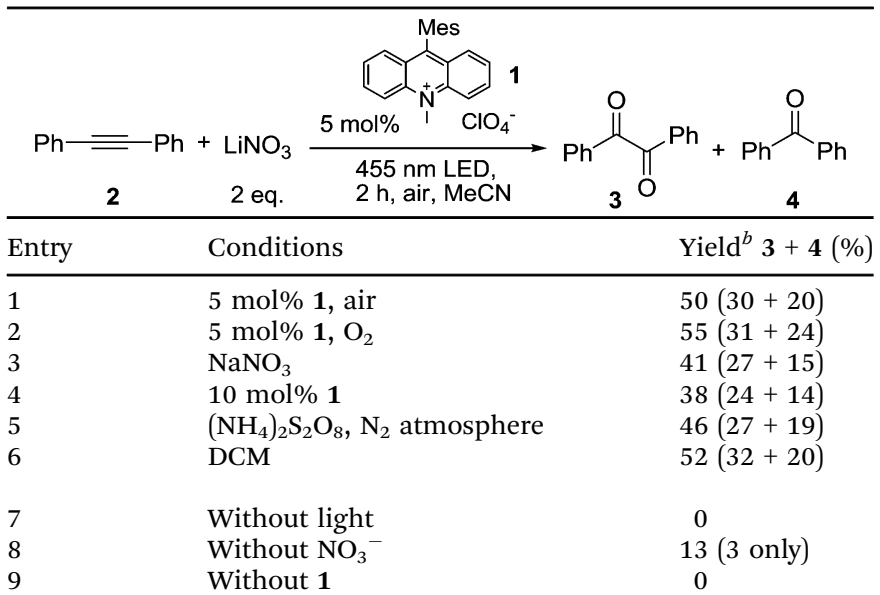

${ }^{a}$ Reactions were carried out using diphenylacetylene $(2,0.25 \mathrm{mmol})$ and the respective amount of 9-mesityl-10-methylacridinium perchlorate (1) in $1 \mathrm{~mL}$ of MeCN unless otherwise noted with an irradiation time of $2 \mathrm{~h}$. ${ }^{b}$ Quantitative GC yields using acetophenone as internal standard.

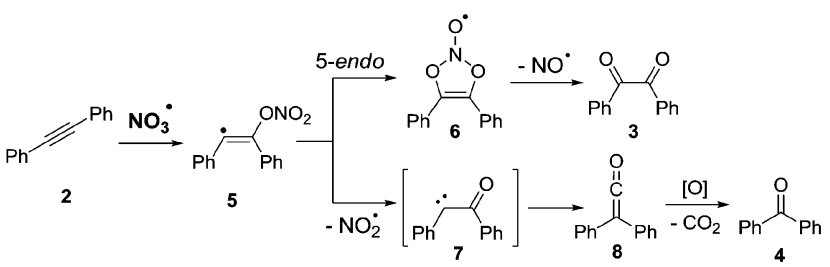

Scheme 2 Proposed mechanism for the oxidation of aromatic alkynes by $\mathrm{NO}_{3} \cdot{ }^{27}$

of $\mathrm{NO}^{*}$, the key-step in the formation of benzophenone (4) is $\gamma$-fragmentation with elimination of $\mathrm{NO}_{2}{ }^{\circ}$, and subsequent Wolff-rearrangement of the carbene intermediate 7 followed by oxidative decarboxylation. ${ }^{27}$

Next, we applied the photocatalytic $\mathrm{NO}_{3} \cdot$ formation to the synthesis of tetrasubstituted tetrahydrofurans, which proceeds via a self-terminating radical cascade that is initiated by $\mathrm{NO}_{3}{ }^{\bullet}$ addition to the triple bond in alkyne 9 . The reaction was described previously using either anodic oxidation of lithium nitrate or CAN photolysis. ${ }^{17,18}$ The starting material 9 (Scheme 3) contains an aliphatic alkyne, which is more difficult to oxidize compared to 2 and thus decreases the background reaction that is caused by direct oxidation of $\mathbf{9}$ by the photocatalyst. The reaction of $\mathbf{9 b}$ with 2 eq. of $\mathrm{LiNO}_{3}$ and $5 \mathrm{~mol} \% 1$ gave the anticipated product 10b in a yield of $37 \%$ ( $67 \%$ based on conversion), with $45 \%$ of the starting material $9 \mathbf{b}$ being recovered. Methyl ether $9 a$ gave lower yields and

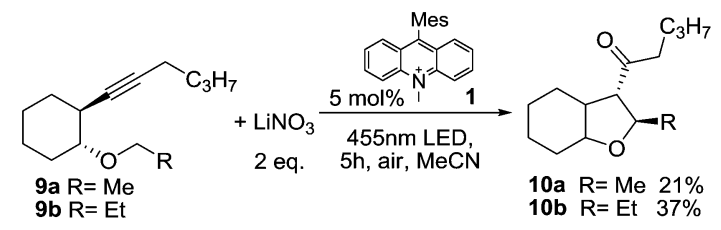

Scheme 3 Self-terminating radical oxidative cyclization to tetrasubstituted tetrahydrofurans $10 .^{17,18}$ 


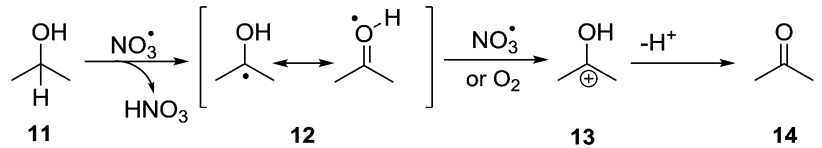

Scheme 4 General mechanism of the nitrate mediated alcohol oxidation via initial hydrogen abstraction followed by oxidation and loss of a proton.

an incomplete conversion, which can be rationalized by a nonregioselective addition of $\mathrm{NO}_{3}{ }^{\bullet}$ to both ends of the alkyne, $\S$ in accordance with previous reports. The low conversion (and resulting low product yield) is likely due to the fact that $\mathrm{NO}_{3} \cdot$ leads to degradation of catalyst 1 . This effect could also be observed in UV/Vis measurements of the reaction mixture, which showed considerable photobleaching of the ground state during irradiation (see Fig. S7 in the ESI $\dagger$ ). It is likely that the observed degradation proceeds via oxidation of the methyl groups on the mesityl moiety of the catalyst, ${ }^{8}$ which is a known degradation pathway that leads to loss of catalytic activity. ${ }^{28}$ The problem of low conversion could be partly overcome through slow addition of the catalyst via syringe pump.

Apart from addition to $\pi$ systems, $\mathrm{NO}_{3}{ }^{\bullet}$ also reacts through hydrogen abstraction, ${ }^{8,12,13}$ which was explored in the catalytic oxidation of non-activated alcohols. In this reaction, $\mathrm{NO}_{3}{ }^{\bullet}$ acts as a redox mediator, which is regenerated during the catalytic cycle, according to the mechanism in Scheme 4. Initial HAT from the alcohol carbon atom by $\mathrm{NO}_{3}{ }^{\bullet 29}$ leads to the regeneration of $\mathrm{NO}_{3}{ }^{-}$as nitric acid and formation of radical 12. The latter is subsequently oxidized by either $\mathrm{NO}_{3}{ }^{\bullet}$ or oxygen to give cationic intermediate 13, which deprotonates to yield ketone $\mathbf{1 4}$. The mechanism is similar to the indirect anodic oxidation of alcohols by nitrate. ${ }^{30}$ Donaldson and Styler reported the enhanced gas phase oxidation of propanol under UV irradiation using $\mathrm{TiO}_{2}$ co-embedded with $\mathrm{KNO}_{3}$. The finding was explained by formation of $\mathrm{NO}_{3}{ }^{\bullet}$ and its ability to abstract hydrogen atoms from the alcohol carbon atom. ${ }^{31}$

The reaction was explored using tert-butyl cyclohexanol (11a) and the results are compiled in Scheme 5. To our delight, oxidation into the corresponding ketone 14a occurred upon irradiation with blue light in the presence of $\mathrm{LiNO}_{3}$ using $5 \mathrm{~mol} \%$ of 1 in acetonitrile. No reaction was observed in the absence of nitrate, which clearly confirms the role of $\mathrm{NO}_{3}{ }^{\circ}$ in this reaction. Stepwise reduction of the amount of $\mathrm{LiNO}_{3}$ from 2 eq. to $20 \mathrm{~mol} \%$ did not affect the outcome, showing that $\mathrm{NO}_{3}{ }^{\bullet}$ can act as mediator in this reaction (Scheme 5). An acidification of the solution due to formation of nitric acid was observed, but no apparent influence on the reaction or the stability of the catalyst was found. $\uparrow$

The scope of this method was explored towards other non-activated alcohols and electron deficient benzyl alcohols.

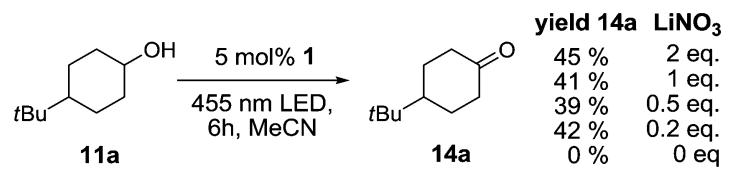

Scheme 5 Experimental conditions and results for the $\mathrm{NO}_{3} \cdot$ mediated oxidation of alcohols.
Table 2 Experimental conditions and results for the $\mathrm{NO}_{3}{ }^{\circ}$ mediated oxidation of alcohols ${ }^{a}$

$\begin{aligned} & \text { Yield } \\ & \text { product } \\ & (\%)\end{aligned}$
$\begin{aligned} & \text { Recovered } \\ & \text { starting } \\ & \text { material }^{b}(\%)\end{aligned}$

${ }^{a}$ Reactions carried out using $0.25 \mathrm{mmol}$ of the alcohol 11, 1 eq. of $\mathrm{LiNO}_{3}$ and $10 \mathrm{~mol} \%$ of 1 (two subsequent additions of $5 \mathrm{~mol} \%$ ) in $1 \mathrm{~mL}$ of MeCN with an irradiation time of $6 \mathrm{~h} .{ }^{b}$ Isolated yields, in brackets yield based on conversion. ${ }^{c}$ Background reaction without $\mathrm{LiNO}_{3}$ is $9 \%$. ${ }^{d}$ Decomposition of substrate 11e.

All reactions were carried out by two sequential additions of $5 \mathrm{~mol} \%$ of $\mathbf{1}$ in order to counteract the loss of catalytic activity caused by degradation of the catalyst. The reactions proceed with good selectivity (see Table 2, entries 1, 2, 4), but the conversion was incomplete and unreacted starting material was recovered. Aliphatic (entries 1-3) and benzylic alcohols (entries 4 and 6) were converted.

In the oxidation of isomenthol (11b) (entry 2) the configuration of the stereocenter remained unchanged, while the basic substrate 11e gave no product, which is most likely due to an acid-base reaction of pyridine with nitric acid that is generated during this reaction $\|$ by the $\mathrm{H}$-abstraction by $\mathrm{NO}_{3}{ }^{\bullet}$ or a possible direct oxidation of the nitrogen of pyridine by the photocatalyst or $\mathrm{NO}_{3}{ }^{\bullet}$ (entry 5 ). ${ }^{32}$

In conclusion, we described a new and simple access to highly reactive nitrate radicals using visible light photocatalysis with an organic dye as the photoredox catalyst. This method avoids the use of toxic compounds, or high electrochemical potentials and is, to the best of our knowledge, the first method yielding $\mathrm{NO}_{3}{ }^{\bullet}$ in a catalytic process using visible light. We verified the formation of nitrate radicals by observation of the reduced catalyst $\mathbf{A c r}^{\bullet}-\mathbf{M e s}$ and showed that the mechanism is proceeding via the singlet excited state of the catalyst. By investigating the addition to aromatic alkynes, a previously well studied model reaction of $\mathrm{NO}_{3}{ }^{\bullet}$, we showed that the photocatalytic procedure is as efficient as the previously employed methods.

Financial support by the Deutsche Forschungsgemeinschaft (DFG), the GRK 1626 and the Australian Research Council is acknowledged. TH thanks the Fonds der Deutschen Chemischen Industrie for a fellowship. 


\section{Notes and references}

\$ After aeration the ground state absorption of $\mathbf{A c r}^{+}$-Mes cannot be fully recovered (see $\mathrm{ESI}_{\dagger}^{\dagger}$ ).

$\S$ For the mechanism of this reaction see ESI. $\dagger$

T The addition of different bases $\left(\mathrm{LiNO}_{3}, \mathrm{LiOAc}\right.$, pyridine, lutidine) did not influence the outcome of the reaction or the stability of the catalyst.

|| Based on the assumption that both the initial hydrogen abstraction and the oxidation of $\mathbf{1 2}$ are done by nitrate radicals.

1 R. P. Wayne, I. Barnes, P. Biggs, J. P. Burrows, C. E. Canosa-Mas, J. Hjorth, G. Le Bras, G. K. Moortgat, D. Perner, G. Poulet, G. Restelli and H. Sidebottom, Atmos. Environ., Part A, 1991, 25, 1-203.

2 M. P. Pérez-Casany, I. Nebot-Gil, J. Sánchez-Marín, F. Tomás-Vert, E. Martínez-Ataz, B. Cabañas-Galán and A. Aranda-Rubio, J. Org. Chem., 1998, 63, 6978-6983.

3 H. Gong, A. Matsunaga and P. J. Ziemann, J. Phys. Chem. A, 2005, 109, 4312-4324.

4 J. C. Harrison and J. R. Wells, Int. J. Chem. Kinet., 2012, 44, 778-788.

5 D. Rousse and C. George, Phys. Chem. Chem. Phys., 2004, 6, 3408-3414.

6 S. Langer, E. Ljungstrom and I. Wangberg, J. Chem. Soc., Faraday Trans., 1993, 89, 425-431.

7 O. Ito, S. Akiho and M. Iino, J. Phys. Chem., 1989, 93, 4079-4083.

8 E. Baciocchi, T. D. Giacco, S. M. Murgia and G. V. Sebastiani, J. Chem. Soc., Chem. Commun., 1987, 1246-1248.

9 H. Suzuki and T. Mori, J. Chem. Soc., Perkin Trans. 2, 1996, 677-683.

10 E. Baciocchi, I. Del Giacco, C. Rol and G. V. Sebastiani, Tetrahedron Lett., 1985, 26, 541-544.

11 T. Shono, M. Chuankamnerdkarn, H. Maekawa, M. Ishifune and S. Kashimura, Synthesis, 1994, 895-897.

12 A. A. Fokin, S. A. Peleshanko, P. A. Gunchenko, D. V. Gusev and P. R. Schreiner, Eur. J. Org. Chem., 2000, 3357-3362.
13 M. Mella, M. Freccero, T. Soldi, E. Fasani and A. Albini, J. Org. Chem., 1996, 61, 1413-1422.

14 U. Wille, Chem. - Eur. J., 2002, 8, 340-347.

15 U. Wille, J. Am. Chem. Soc., 2001, 124, 14-15.

16 U. Wille, Chem. Rev., 2012, 113, 813-853.

17 U. Wille and L. Lietzau, Tetrahedron, 1999, 55, 11465-11474.

18 U. Wille and L. Lietzau, Tetrahedron, 1999, 55, 10119-10134.

19 L. F. Gamon, J. M. White and U. Wille, Org. Biomol. Chem., 2014, 12, 8280-8287.

20 D. C. E. Sigmund and U. Wille, Chem. Commun., 2008, 2121-2123.

21 S. Fukuzumi, H. Kotani, K. Ohkubo, S. Ogo, N. V. Tkachenko and H. Lemmetyinen, J. Am. Chem. Soc., 2004, 126, 1600-1601.

22 K. Ohkubo, K. Mizushima, R. Iwata, K. Souma, N. Suzuki and S. Fukuzumi, Chem. Commun., 2010, 46, 601-603.

23 N. A. Romero and D. A. Nicewicz, J. Am. Chem. Soc., 2014, 136, 17024-17035.

24 K. Ohkubo, K. Mizushima and S. Fukuzumi, Res. Chem. Intermed., 2013, 39, 205-220.

25 S. Fukuzumi, K. Ohkubo and T. Suenobu, Acc. Chem. Res., 2014, 47, $1455-1464$.

26 A. C. Benniston, A. Harriman, P. Li, J. P. Rostron, H. J. van Ramesdonk, M. M. Groeneveld, H. Zhang and J. W. Verhoeven, J. Am. Chem. Soc., 2005, 127, 16054-16064.

27 U. Wille and J. Andropof, Aust. J. Chem., 2007, 60, 420-428.

28 A. C. Benniston, K. J. Elliott, R. W. Harrington and W. Clegg, Eur. J. Org. Chem., 2009, 253-258.

29 S. Langer and E. Ljungstrom, J. Chem. Soc., Faraday Trans., 1995, 91, 405-410.

30 D. Kyriacou, Modern Electroorganic Chemistry, Springer-Verlag, Berlin, Heidelberg, 1994.

31 S. A. Styler and D. J. Donaldson, Environ. Sci. Technol., 2011, 45, 10004-10012.

32 A. Thellend, P. Battioni, W. Sanderson and D. Mansuy, Synthesis, 1997, 1387-1388. 